\title{
Theories of Endometrial Carcinogenesis: A Multidisciplinary Approach
}

\author{
Mark E. Sherman, M.D. \\ Departments of Pathology and Gynecology and Obstetrics, The Johns Hopkins Medical Institutions, \\ Baltimore, Maryland
}

Historical observations have suggested that endometrial carcinomas vary in histopathologic appearance and clinical features. More recent, systematic studies have provided epidemiologic, clinicopathologic, and molecular support for these observations. Specifically, studies suggest that the most common type of endometrial carcinoma, endometrioid adenocarcinoma, develops from endometrial hyperplasia in the setting of excess estrogen exposure and usually pursues an indolent clinical course. In contrast, a minority of endometrial carcinomas, best represented by serous carcinoma, do not seem to be related to estrogenic risk factors or elevated serum hormone levels, and these tumors seem to develop from atrophic rather than hyperplastic epithelium. We have proposed that serous carcinomas develop from "endometrial intraepithelial carcinoma," a lesion representing malignant transformation of the endometrial surface epithelium. Whereas endometrioid carcinoma and endometrial hyperplasia are associated with microsatellite instability and ras and PTEN mutations, serous carcinoma and endometrial intraepithelial carcinoma are associated with $p 53$ mutations and abnormal accumulation of p53 protein. Based on these data regarding the pathogenesis of endometrioid and serous carcinoma, we have proposed a dualistic model of endometrial carcinogenesis incorporating a "classic" estrogen-driven pathway and an "alternative" pathway seemingly unrelated to hormones. It is hoped that further studies may permit the extension and modification of this model and that these advances will lead to improved diagnosis, management, and prevention.

Copyright () 2000 by The United States and Canadian Academy of Pathology, Inc.

VOL. 13, NO. 3, P. 295, 2000 Printed in the U.S.A.

Date of acceptance: November 8, 1999.

Address reprint requests to: Mark E. Sherman, M.D., Associate Professor of Pathology and Gynecology and Obstetrics, The Johns Hopkins Medical Institutions, Department of Pathology, Ross 659, 720 Rutland Avenue, Baltimore, MD 21205; e-mail: msherma@jhmi.edu; fax: 410-614-3548.
KEY WORDS: Carcinogenesis, Carcinoma, Endometrioid, Endometrium, Epidemiology, Pathology, Serous

Mod Pathol 2000;13(3):295-308

The goal of this review is to propose a dualistic model of endometrial carcinogenesis that incorporates two pathways that differ in regard to epidemiologic risk factors, histopathologic lesions, and molecular events (1). The "classic" pathway is proposed as a mechanism by which indolent tumors develop from hyperplastic precursors in an estrogen-rich milieu. In contrast, the "alternative" pathway is thought to account for the development of many aggressive tumors that are not associated with hyperplasia or estrogen excess. This dualistic model represents an extension of clinicopathologic observations published nearly 2 decades ago.

Based on clinicopathologic observations in 366 endometrial cancers, Bokhman (2) proposed that there are two main types of endometrial carcinomas: type 1 tumors related to hormonal imbalances and type 2 tumors that seem largely unrelated to estrogen. According to this model, type 1 tumors are indolent neoplasms that are associated with hyperlipidemia, obesity, and signs of hyperestrogenism, such as anovulatory bleeding, infertility, late menopause, and endometrial and ovarian stromal hyperplasia. Type 2 tumors are unrelated to these features, behave aggressively, and lack the progesterone responsiveness of type 1 tumors. Building on these clinical observations, it has been suggested that the majority of type 1 tumors correspond to the endometrioid type of endometrial carcinoma, whereas type 2 tumors probably include most serous carcinomas and some other aggressive types (1). Although the correspondence between specific histopathologic tumor types and risk factors is imperfect, this generalization has been used to propose a dualistic model of endometrial carcinogenesis that may prove useful in planning future etiologic studies and, ultimately, in clinical practice. Accordingly, the terms type 1 and endometrioid and the terms type 2 and serous are used interchangeably in this article. 


\section{EPIDEMIOLOGIC OBSERVATIONS}

Endometrial carcinoma ranks first in incidence and second in mortality among female genital tract tumors, with projections of 37,400 new cases and 6,400 related deaths among women in the United States in 1999 (3). Incidence rates for endometrial carcinoma have remained stable at 20/100,000 women-years since the 1970s, when rates climbed to more than $30 / 100,000$ in conjunction with widespread use of unopposed estrogen among postmenopausal women. Decline in the use of these hormone preparations was paralleled by a decrease in endometrial cancer incidence, supporting the role of excess estrogen exposure in endometrial carcinogenesis. Data from the population-based Surveillance and Epidemiology End Results Program indicate that incidence rates are $60 \%$ higher among whites, whereas mortality is $30 \%$ higher among African Americans (4). It is unclear whether these mortality data reflect interracial differences in diagnosis and treatment or an unexplained tendency for African Americans to develop aggressive tumors that are disproportionately high grade, often contain p53 abnormalities, and frequently are serous or clear cell in type (5-8). Because population-based screening programs for endometrial carcinoma have not been developed in the United States, our knowledge of the frequency and natural history of endometrial cancer precursors is limited. Many endometrial hyperplasias could be asymptomatic and regress spontaneously without ever being detected. Etiologic and mechanistic studies have been largely limited to the biased fraction of cases that are persistent and produce clinical symptoms and those associated with invasive carcinoma.

Most epidemiologic studies have analyzed all types of endometrial carcinoma as a single entity, rather than consider different histopathologic types separately. Because endometrioid carcinomas comprise over $80 \%$ of endometrial carcinomas and most endometrioid tumors are type 1 tumors, epidemiologic studies have promoted the view that nearly all endometrial cancer risk factors are mediated through estrogen and that protective factors act by opposing estrogen. Published data regarding endometrial cancer risk factors have been recently summarized in detail (4). Selected exposures related to endometrial carcinoma are presented in Table 1.

Risk associated with exogenous estrogen use among postmenopausal women is related to duration of exposure, with approximately 10-fold increases associated with a decade of use. Menstrual factors, such as early menarche and late menopause, and nulliparity are thought to increase cumulative estrogen exposure by increasing a wom-
TABLE 1. Selected Epidemiologic Exposures Related to Endometrial Carcinoma

\begin{tabular}{ll}
\hline \multicolumn{1}{c}{ Risk Factors } & \multicolumn{1}{c}{ Protective Factors } \\
\hline Exogenous estrogen & Oral contraceptives (progesterone) \\
Menstrual factors & Smoking \\
Nulliparity & \\
Polycystic ovary disease & \\
Estrogen-producing tumors & \\
Obesity & \\
Tamoxifen & \\
\hline
\end{tabular}

an's total lifetime number of menstrual cycles. Even in polycystic ovary disease, which is characterized by virilization, it is postulated that chronically elevated luteinizing hormone levels promote increased androstenedione production by the ovary, which in turn is converted to estrone in peripheral tissue stores. Because adipose tissue and other peripheral stores are a major source of aromatase, an enzyme that converts androgens to estrogens, obesity is believed to confer risk in postmenopausal women by promoting increased production of estrogen from adrenal and ovarian androgens. However, it is unclear whether the risk associated with obesity is entirely attributable to elevations in serum estrogen, and the possibility that nonhormonal mechanisms may be involved has been considered. Tamoxifen is a nonsteroidal estrogen agonist and antagonist that may have nonhormonal effects, including the formation of DNA adducts. Although tamoxifen use increases endometrial cancer risk, data are conflicting as to whether type 1 or type 2 tumors predominate, perhaps reflecting the dualistic action of this drug. Protective factors are believed to operate by opposing the actions of estrogen. For example, oral contraceptives contain progesterone, which may directly oppose the effects of estrogen, and smoking may reduce estrogen levels by producing alterations in hormone metabolism.

\section{EPIDEMIOLOGIC EVIDENCE FOR TWO PATHWAYS OF ENDOMETRIAL CARCINOGENESIS}

In a past study, data from 328 endometrioid and 26 serous carcinomas and 320 population-based controls without endometrial cancer were analyzed to evaluate whether epidemiologic data support a dualistic model of endometrial carcinogenesis (9). In that analysis, the average age of patients with serous carcinomas was 6 years greater than that of patients with endometrioid carcinoma. Predictably, obesity and exogenous hormone use were associated with increased risk for endometrioid carcinoma, but these exposures were not related to risk for serous carcinoma. However, concurrent smoking and oral contraceptive use were protective for 
both tumor types. Comparison of selected serum hormone levels, determined using validated laboratory assays, demonstrated that both estrogens and androgens were elevated in women with endometrioid carcinoma, compared with controls, whereas levels for patients with serous carcinoma were similar to those in the controls (Table 2). In contrast, levels of sex-hormone-binding globulin, a circulating protein that reduces bioavailable estrogen, were higher among serous carcinoma patients than controls or endometrioid carcinoma patients. Because serum hormone data were adjusted for age and body mass index (a measure of obesity), the differences in levels between endometrioid and serous carcinoma patients do not merely reflect the fact that women with serous carcinoma are older and thinner. These results suggest a fundamental difference in the hormonal milieu in which these two types of tumors develop. In summary, available epidemiologic data support the proposed dualistic model of endometrial carcinogenesis, but the analyses are limited by the small number of serous carcinoma patients studied. Although these data suggest that exogenous estrogen use is not a risk factor for serous carcinoma, there are no data to suggest that estrogen is protective against the development of these tumors.

Many questions regarding endometrial cancer risk factors persist (10). For example, what changes occur at the cellular level to explain why exposures early in life (e.g., oral contraceptive use) reduce cancer risk decades after the exposure has ended? Why is the increased risk associated with elevated serum estrogen levels relatively modest if endometrial carcinoma results from systemic estrogenism, and why are elevated androgens associated with increased risk? Are these observations only artifacts of study designs that rely on single hormone measurements in postmenopausal women, or do these findings reflect the fundamental complexity inherent in understanding the chronic exposures that lead to cancer? Finally, the recognition that some endometrioid carcinomas arise in patients lacking classic risk factors and that endometrial hyperpla-

TABLE 2. Comparison of Mean Levels of Selected Hormones in Endometrioid (Type 1) and Serous (Type 2) Carcinomas

\begin{tabular}{lccc}
\hline \multicolumn{1}{c}{ Hormone } & $\begin{array}{c}\text { Endometrioid } \\
\text { (Type 1) } \\
\text { Carcinoma }\end{array}$ & $\begin{array}{c}\text { Serous } \\
\text { (Type 2) } \\
\text { Carcinoma }\end{array}$ & Control \\
\hline Estrogen $(\mathrm{pg} / \mathrm{mL})$ & 9.8 & 8.1 & 7.6 \\
Free estrogen $(\mathrm{pg} / \mathrm{mL})$ & 0.16 & 0.12 & 0.11 \\
Estrone $(\mathrm{pg} / \mathrm{mL})$ & 42.0 & 33.7 & 32.6 \\
Androstenedione $(\mathrm{ng} / \mathrm{dL})$ & 76.2 & 64.4 & 59.0 \\
SHBG $(\mathrm{nmol} / \mathrm{L})$ & 31.3 & 41.4 & 36.3 \\
\hline
\end{tabular}

SHBG, Sex hormone-binding globulin. sia is not always identified in uteri containing endometrioid carcinoma raises the question as to whether some endometrioid carcinomas represent type 2 tumors. However, in an analysis that examined the relationship between different patterns of endometrioid carcinoma and risk factors, differences were not identified among tumors stratified by grade, stage, presence of squamous differentiation, or endometrial hyperplasia (11). Continued research on this topic is needed.

\section{CLINICOPATHOLOGIC EVIDENCE FOR TWO PATHWAYS OF ENDOMETRIAL CARCINOGENESIS}

Histopathologic support for an alternative pathway of endometrial carcinogenesis unrelated to hormone imbalances is derived largely from clinicopathologic studies of serous carcinoma. In a seminal report, Hendrickson et al. (12) reported that serous carcinomas accounted for $50 \%$ of recurrences in a series of 256 clinical Stage I tumors, even though only $10 \%$ of these tumors were serous. These authors emphasized that women with serous carcinoma were considerably older than those with endometrioid carcinoma and that serous tumors behaved more aggressively than even Grade 3 endometrioid tumors. In addition, this report highlighted the similar morphology of uterine serous carcinoma and its homologue in the ovary and the tendency for both tumors to produce ascites and spread along peritoneal surfaces.

Another contribution of this study, and possibly the finding that received the most immediate attention, was the development of criteria for distinguishing the two main types of uterine papillary carcinoma: villoglandular endometrioid carcinoma and serous carcinoma. Classic examples of serous carcinoma demonstrate coarse, edematous papillae lined by cuboidal, low columnar, or hobnail-shaped cells displaying anaplastic nuclear cytology and mitoses, often including abnormal figures. In contrast, the papillae in villoglandular carcinoma are generally thinner and more uniform, and most important, the cells lining the papillae are columnar in shape, monomorphic, and display minimal nuclear atypia (Fig. 1). In summary, the report of Hendrickson et al. (12) clarified the confusion regarding the two main types of papillary carcinomas that occur in the uterus and paved the way for broadening the morphologic criteria for diagnosing serous carcinoma.

Recent studies have emphasized that serous carcinomas vary widely in appearance to include tumors composed largely or exclusively of gaping 

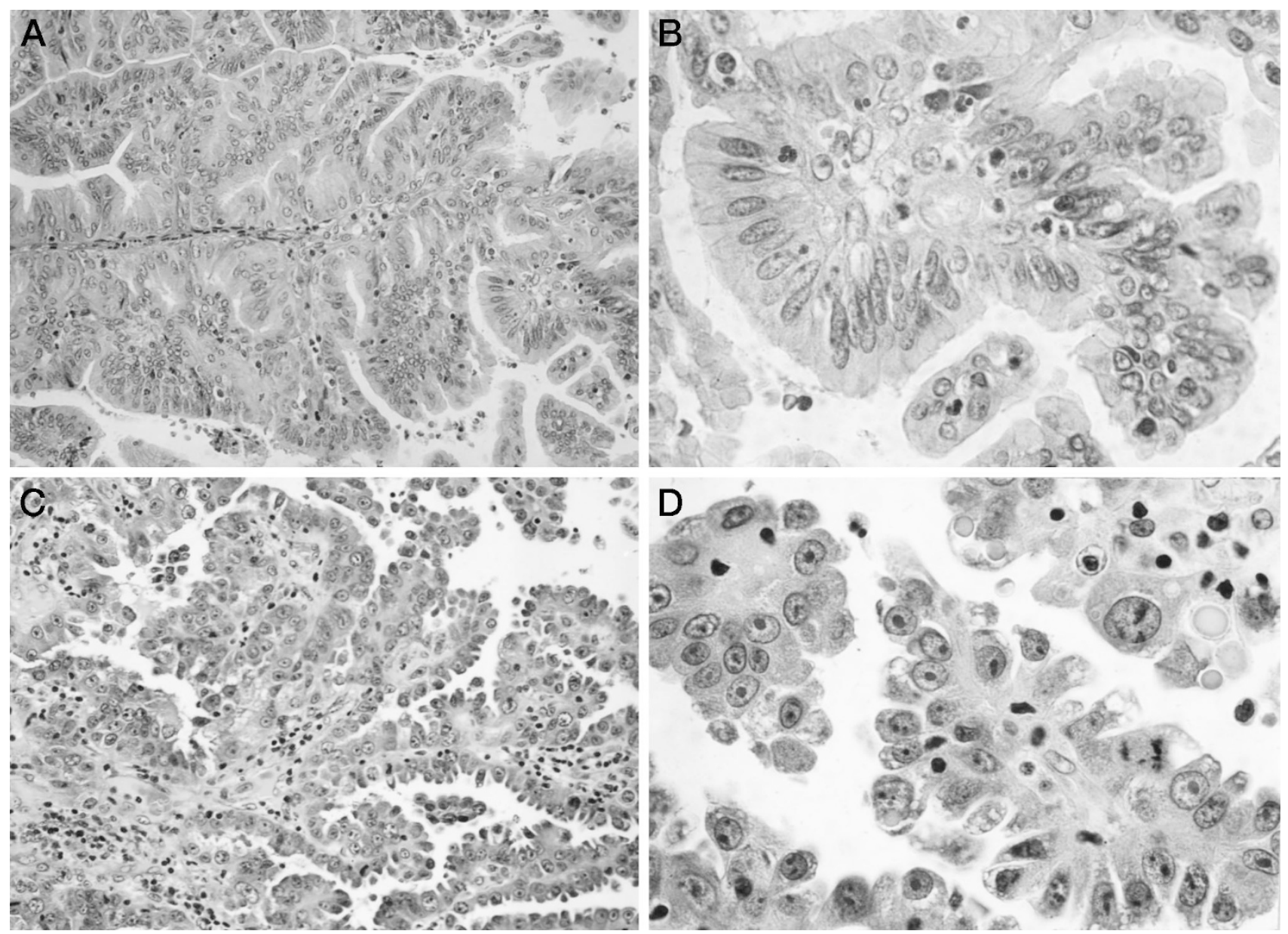

FIGURE 1. A, endometrioid carcinoma, villoglandular type. Note delicate fibrovascular core with bulbous, uniform-appearing fronds. B, endometrioid carcinoma, villoglandular type. Columnar cells lining the papillae possess bland ovoid nuclei. C, serous carcinoma. Papillae are well formed with broad edematous fibrovascular cores. D, serous carcinoma. Cells contain round nuclei with irregularly distributed chromatin, macronucleoli, and mitoses.

glands with intraluminal papillary proliferations, tumors associated with benign polyps, and mixed tumors in which serous carcinoma coexists with endometrioid, clear cell, or other differentiation patterns (13). The unifying feature that distinguishes serous carcinoma from endometrioid carcinoma is that in serous carcinoma, welldifferentiated architecture, defined as formation of glands or papillae, is usually associated with highgrade nuclear atypia, whereas in endometrioid carcinoma, architectural and nuclear grade are nearly always concordant (Fig. 2). Because all serous carcinomas are high-grade by definition, grading is superfluous, and in contrast to endometrioid carcinomas, depth of myometrial invasion does not accurately predict stage. Tumors with mixed differentiation, in which $25 \%$ of the neoplasm appears serous, usually behave as aggressively as pure serous carcinoma; consequently, we regard these tumors as serous carcinoma for clinical purposes. However, we suspect that the etiology and pathogenesis of some mixed tumors may differ from that of pure serous carcinoma (see below).

\section{EVIDENCE FROM PRECURSOR STUDIES SUPPORTING THE EXISTENCE OF TWO PATHWAYS OF ENDOMETRIAL CARCINOGENESIS}

Atypical endometrial hyperplasia (AH) undoubtedly represents the precursor of many, but possibly not all, endometrioid (type 1) carcinomas. The similar appearance of $\mathrm{AH}$ and Grade 1 endometrioid carcinoma underscores the pathogenetic relationship between the two lesions. In addition, $\mathrm{AH}$ and endometrioid carcinoma are often present concurrently and in topographic proximity in hysterectomy specimens. Furthermore, natural history studies have demonstrated that a significant percentage of AHs progress to carcinoma if untreated. Finally, recent studies have demonstrated similar immunohistochemical and molecular markers in the two lesions.

Natural history studies have provided us with insights into endometrial carcinogenesis, despite the limitations imposed by the lack of populationbased screening data. Most cases of endometrial 


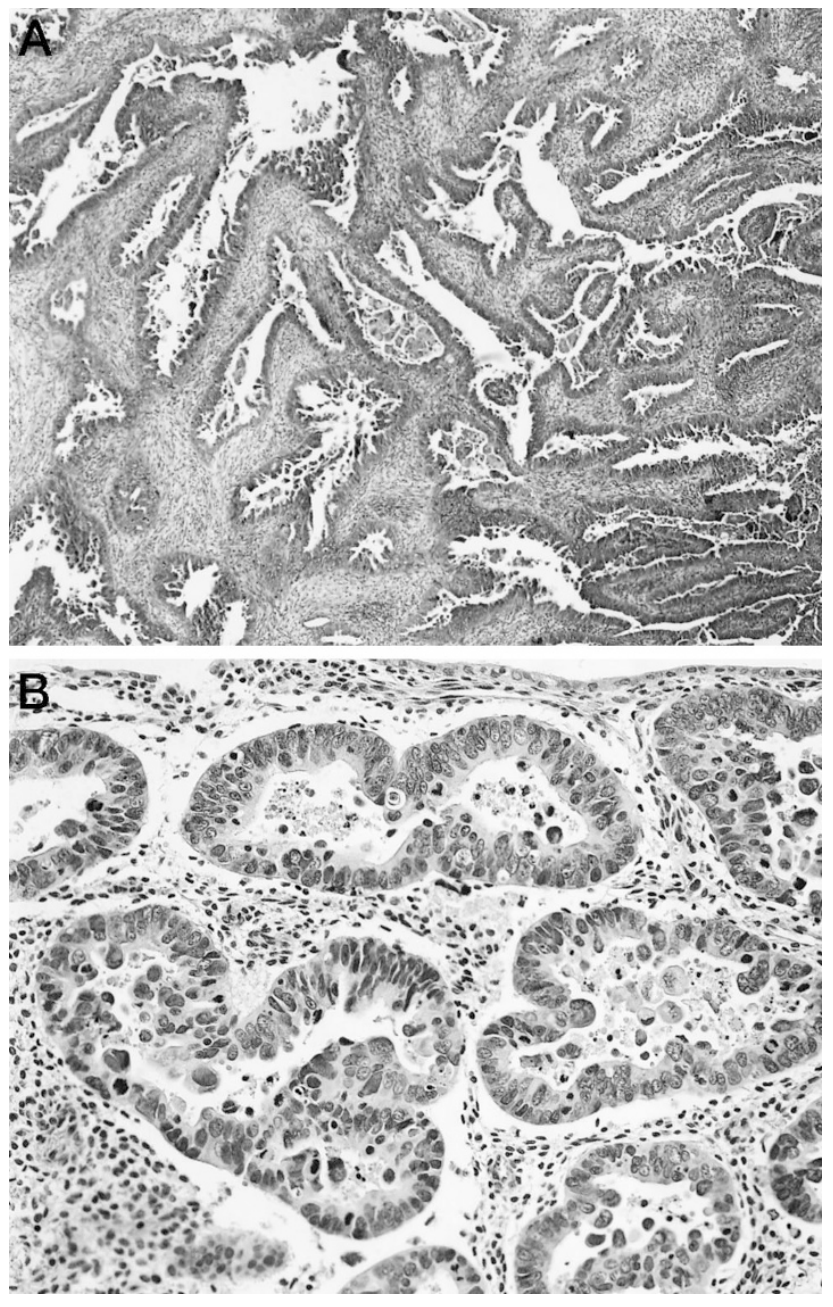

FIGURE 2. A, serous carcinoma, glandular pattern. Large glands show open, irregularly shaped lumina with papillary infoldings. B, serous carcinoma, glandular pattern. Cells with anaplastic nuclei form glands that are architecturally well differentiated.

hyperplasia that have been studied were identified because of symptoms (causal or coincidental) or surveillance related to specific risk factors (e.g., hormone replacement), or they were discovered serendipitously in women investigated for other pathology. Furthermore, these lesions were often treated or rebiopsied for clinical indications, which may have altered their natural history in an unpredictable manner. Nonetheless, these studies are revealing. For example, Kurman et al. (14) reported the follow-up of 170 patients with endometrial hyperplasia, diagnosed at the Armed Forces Institute of Pathology, who were followed for at least 1 year without hysterectomy. Most lesions of all types regressed, including $80 \%$ of both simple and complex hyperplasias without atypia. Hyperplasia without atypia progressed to carcinoma only rarely, whereas $8 \%$ of atypical simple and $29 \%$ of atypical complex hyperplasias progressed. These data suggest that most hyperplasias without atypia probably represent early, highly reversible lesions in the pathogenesis of endometrial carcinoma. Although every untreated $\mathrm{AH}$ may not progress to carcinoma and some endometrioid (type 1) carcinomas may arise without hyperplasia, these data support the thesis that $\mathrm{AH}$ is the immediate precursor of endometrioid carcinoma.

The recognition that $\mathrm{AH}$ and endometrioid carcinoma express both estrogen and progesterone receptors is consistent with the status of $\mathrm{AH}$ as a precursor lesion and suggests that progesterone therapy may permit the reversal of these lesions in young women seeking to retain fertility. Randall and Kurman (15) reported that 16 (94\%) of 17 women with $\mathrm{AH}$ and 9 (75\%) of 12 with endometrioid carcinoma were successfully treated with 3 to 18 months of progesterone, enabling 5 women to become pregnant. Residual hyperplasia was identified in three women treated for $\mathrm{AH}$ and three with carcinoma. Kim et al. (16) reported the results of seven young women treated for carcinoma and reviewed the outcomes of 14 published cases. They reported that an initial response was achieved in $13(62 \%)$ of 21 patients, but 3 patients recurred, including one with metastases. Ferenczy et al. (17) reported that $52(80 \%)$ of 65 postmenopausal women (mean age, $56 \mathrm{y}$ ) with hyperplasia without atypia responded to hormonal therapy; however, only 5 (25\%) of 20 women with $\mathrm{AH}$ regressed, and an equal percentage progressed to carcinoma. In aggregate, these data suggest that both $\mathrm{AH}$ and endometrioid carcinoma in young women are highly reversible, at least in the short term, when treated with progesterone. However, $\mathrm{AH}$ in older women may differ biologically from its counterpart in younger women because it is less responsive to hormonal therapy. This finding is intriguing because it has been hypothesized that the hormonal imbalances leading to carcinoma differ in pre- and postmenopausal women. Imbalances in young women may reflect a relative lack of progesterone, whereas in older women, an absolute excess of estrogen may be involved.

In contrast to the findings in uteri removed for endometrioid (type 1) carcinoma, the uninvolved endometrium in uteri containing serous carcinoma (type 2) is usually atrophic. In one study, $76 \%$ of serous carcinomas were associated with atrophy and $5 \%$ with hyperplasia, whereas $29 \%$ of endometrioid carcinomas were associated with atrophy and $46 \%$ with hyperplasia (18). Endometrial hyperplasia is a more frequent finding in uteri removed for mixed endometrioid/serous carcinomas than in uteri removed for pure serous carcinoma. Carcangiu et al. (19) identified associated endometrial hyperplasia in $46 \%$ of uteri removed for mixed tumors, as opposed to only $8 \%$ with pure serous carcinomas. It has been shown that when endometrial hyperplasia is identified in a uterus containing a carcinoma that is partly or exclusively serous, the 
hyperplasia and the carcinoma are usually topographically unrelated and appear distinct. Therefore, we suggest that mixed endometrioid/serous carcinomas may begin as endometrioid carcinomas that arise from $\mathrm{AH}$ and that serous differentiation develops secondarily in these already established endometrioid carcinomas through a process of clonal evolution. Consequently, we think that the classification of mixed endometrioid/serous carcinomas as serous is appropriate for clinical management but may be unsatisfactory from an etiologic point of view. To my knowledge, this hypothesis has not been systematically assessed in a large series using molecular techniques.

Histopathologic studies suggest that the majority of serous carcinomas develop from a distinctive lesion termed endometrial intraepithelial carcinoma (EIC), which appears to represent malignant transformation of atrophic surface endometrium $(13,18)$. EIC has been identified in $89 \%$ of uteri containing serous (type 2) carcinoma (18). Spiegel (20) and Zheng et al. (21) have described lesions resembling EIC as "endometrial carcinoma in situ" and as "uterine surface carcinoma," respectively. We prefer the term EIC, because "endometrial carcinoma in situ" has been applied historically to an entirely different lesion and "uterine surface carcinoma" may be incorrectly interpreted as suggesting that the prognosis of pure EIC and serous carcinoma are identical (see below).

EIC is characterized by the replacement of benign surface endometrium and underlying glands by cells with anaplastic nuclei resembling serous carcinoma (Fig. 3). EIC should not be diagnosed in areas in which the surface tumor appears to represent overgrowth of an adjacent invasive carcinoma. EIC may consist of a single or multilayered epithelium with or without micropapillary tufting. Cytologically, the cells show marked nuclear membrane irregularities, chromatin that varies from vesicular to smudgy, mitoses including abnormal forms, and apoptotic bodies. EIC may be found in the absence of invasive serous carcinoma, and like the latter, EIC demonstrates strong, diffuse immunostaining for p53 protein and Ki-67 and $p 53$ gene mutations $(1,21,22)$. Noninvasive lesions resembling EIC, termed "intraepithelial carcinoma," may be identified in approximately $25 \%$ of serous carcinoma patients in the endocervix, fallopian tube, and peritoneum and on the surface of the ovary (Fig. 4) (13). In summary, the resemblance of EIC to invasive serous carcinoma, its association with p53 mutation, and its identification in uteri that do not contain invasive serous carcinoma support its proposed designation as a precursor of serous (type 2) carcinoma.

Because we advocate immediate hysterectomy and staging for all women with EIC, even in the
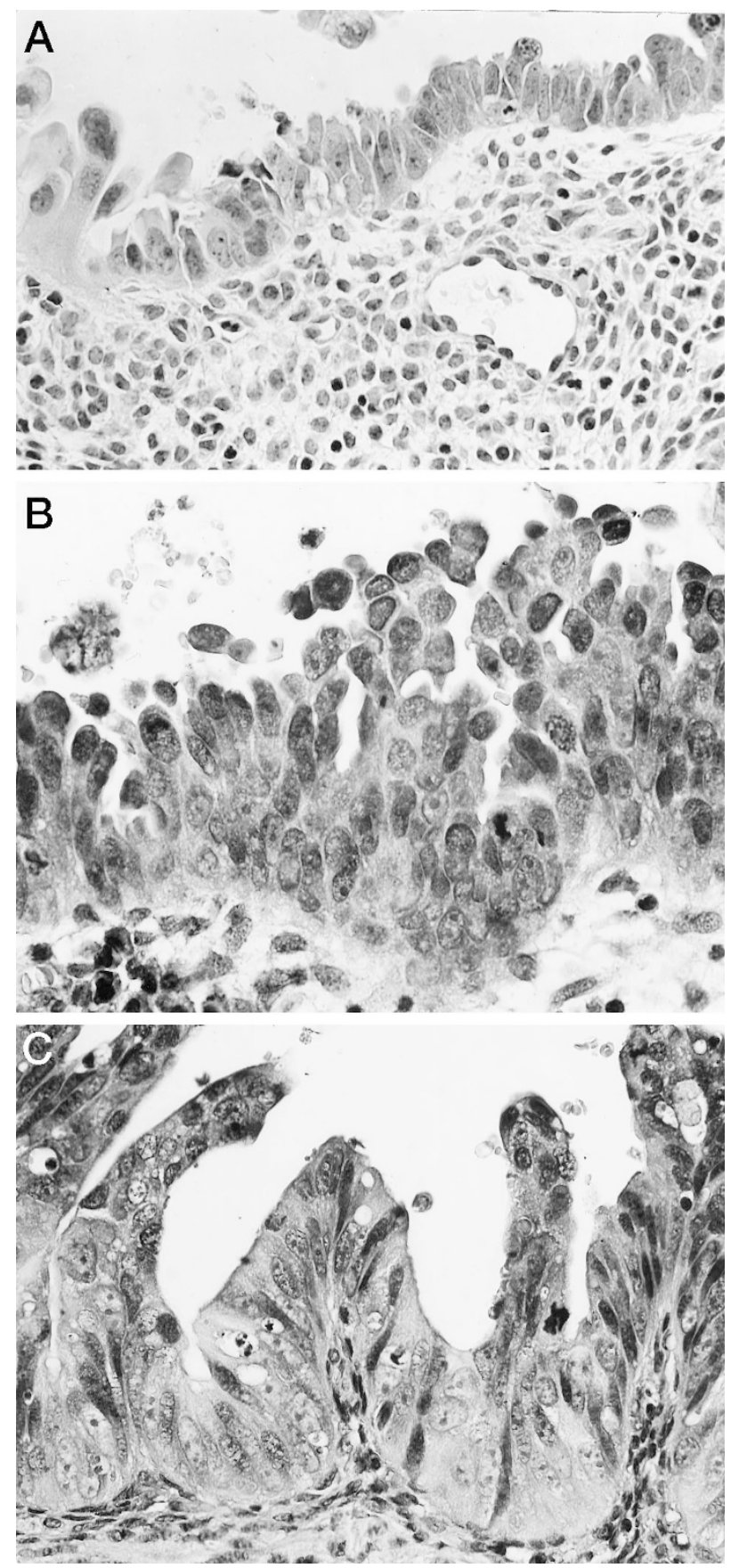

FIGURE 3. Endometrial intraepithelial carcinoma. A, surface endometrium is replaced by a monolayer of pleomorphic cells containing large, atypical nuclei. Underlying endometrium is atrophic and consists mainly of stroma. B, multilayered epithelium composed of cells with Grade 3 nuclei containing mitotic figures. C, cells with Grade 3 nuclei form micropapillae on endometrial surface.

absence of invasion, we know relatively little about the natural history of this lesion. However, we have reviewed eight cases of pure EIC that were not associated with invasion in the uterus, two of which were present in biopsies performed up to 7 and 17 months before hysterectomy. The uteri of these two patients showed EIC only without invasion, and both are alive and well. The benign course in these cases suggests that EIC does not merely reflect the 


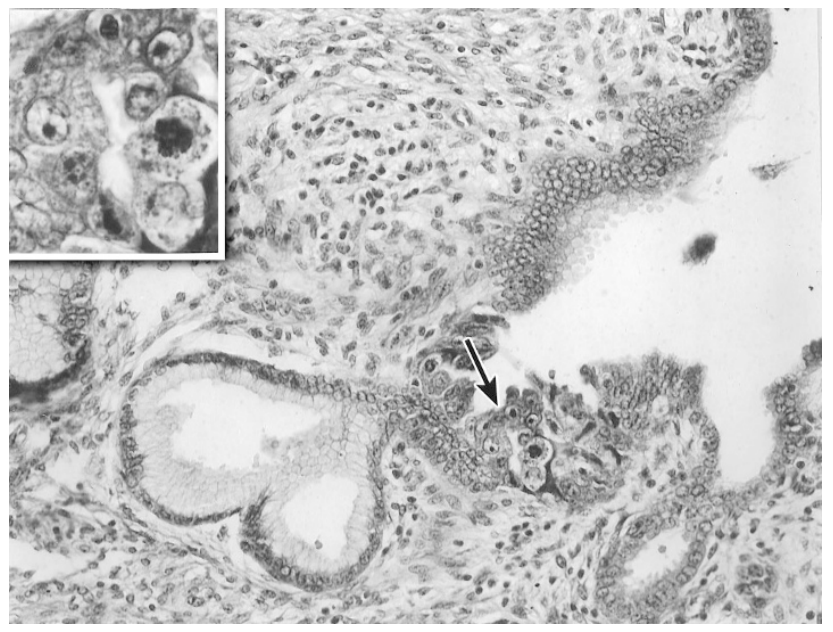

FIGURE 4. Intraepithelial carcinoma involving endocervix. Lining of endocervical gland shows partial intermittent replacement by markedly atypical cells. Inset, Note nuclear irregularities and macronucleoli.

spread of invasive serous carcinoma on the surface of the uterus, and it indicates that EIC does not necessarily progress to invasion within months. However, there are many reported examples of women with lesions that we would probably classify as EIC and that have been associated with extrauterine disease, despite the lack of identifiable endometrial stromal or myometrial invasion $(13,19$, 23-25). In these cases, extrauterine disease may reflect multifocality, transtubal expulsion with implantation and growth or occult invasion in the uterus with lymphatic or hematogenous dissemination.

The differential diagnosis of EIC includes both benign reparative/metaplastic changes and surface changes associated with other tumor types. Features favoring EIC include patient age over 60 years, a background of atrophic endometrium, and strong, diffuse p53 and Ki-67 immunostaining (1, 18, 21). Eosinophilic metaplasia with atypia may pose an especially challenging differential diagnosis, but metaplastic lesions are usually more focal and the cells show degenerative, smudgy chromatin lacking well-preserved nuclear features of malignancy. In addition, metaplasias occur more often in perimenopausal women who are generally about 10 to 15 years younger than women with EIC. Some cases of eosinophilic metaplasia are associated with endometrial hyperplasia or endometrioid carcinoma, whereas in many others, the remaining endometrium is normal. The endometrium adjacent to a minor percentage of endometrioid carcinomas shows focal surface changes resembling EIC, but these lesions usually measure less than a low power microscopic field and are less cytologically atypical than EIC. In addition, the base of an exophytic endometrioid carcinoma that remains after subtotal removal by biopsy or curettage may also mimic EIC. EIC tends to spread into benign glands, often showing partial replacement of the benign epithelium or pagetoid involvement with intercalation between the basement membrane and the normal epithelium. Lesions associated with endometrioid carcinoma that mimic EIC do not typically show this pattern of intramucosal spread. Intraepithelial carcinoma in the fallopian tube and ovary may be indistinguishable from second primary tumors and may represent synchronous carcinomas in some cases. Intraepithelial carcinoma in the endocervix differs from adenocarcinoma in situ of the cervix, because the cells in EIC are generally polygonal rather than columnar, show greater architectural disarray and pleomorphism, and possess round nuclei with prominent nucleoli instead of elongate hyperchromatic nuclei lacking visible nucleoli.

\section{MOLECULAR EVIDENCE FOR TWO PATHWAYS OF ENDOMETRIAL CARCINOGENESIS}

Most molecular studies of endometrial carcinoma have consisted of small series reported from single institutions. Many studies have used frozen samples, probably resulting in a bias toward inclusion of larger, grossly identifiable lesions. Finally, some discrepancies between studies may reflect variations in histopathologic typing of tumors, use of fixed as opposed to frozen tissue, and technical differences in the performance and interpretation of assays. Nonetheless, studies have produced several consistent findings that support the proposed model of carcinogenesis as summarized in Table 3 and as described below.

TABLE 3. Comparison of Selected Molecular Markers in Serous (Type 1) Carcinoma and Endometrioid (Type 2) Carcinoma and Their Respective Precursors

\begin{tabular}{lllll}
\hline Histology & $\begin{array}{c}\text { Diffuse p53+ } \\
\text { Immunostaining }\end{array}$ & $\begin{array}{c}\text { Microsatellite } \\
\text { Instability }\end{array}$ & PTEN Mutation & ras Mutation \\
\hline Hyperplasia & Neg & $+20 \%$ (Ca present) & $+20 \%($ Ca absent) & $+20 \%$ \\
Endometrioid & + Rarely & $+20 \%$ & $+40 \%$ & $+20 \%$ \\
EIC & $+75-100 \%$ & Neg & Neg & + \\
Serous & $+75-100 \%$ & Neg & Neg & Neg \\
\hline
\end{tabular}

ER/PR, estrogen receptor/progesterone receptor; EIC, endometrial intraepithelial carcinoma; Neg, negative; +, present; Ca, carcinoma; ?, unknown; $\uparrow$, high percentage in. 


\section{p53 Mutation}

Mutations in the $p 53$ tumor suppressor gene and accumulation of $\mathrm{p} 53$ protein have been detected in approximately $90 \%$ of serous carcinomas and EIC $(1,22)$ but comparatively rarely in endometrioid carcinomas. Most endometrioid carcinomas that harbor $p 53$ mutations are large high-grade tumors, suggesting that $p 53$ mutation in endometrioid carcinoma is more closely related to dedifferentiation as is the case in other tumor systems.

Because wild type p53 protein has a short halflife, it is generally undetectable in normal cells, whereas mutant p53 protein is more stable and often reaches immunohistochemically detectable levels. Accordingly, immunohistochemistry has been used as an imperfect surrogate marker for $p 53$ gene mutation. However, reported results for p53 immunostaining in endometrial carcinoma have been conflicting because of differences in histopathologic classification, preparation of fresh or fixed tissue, use of different antibodies, differences in staining protocols, criteria for determining "pos-

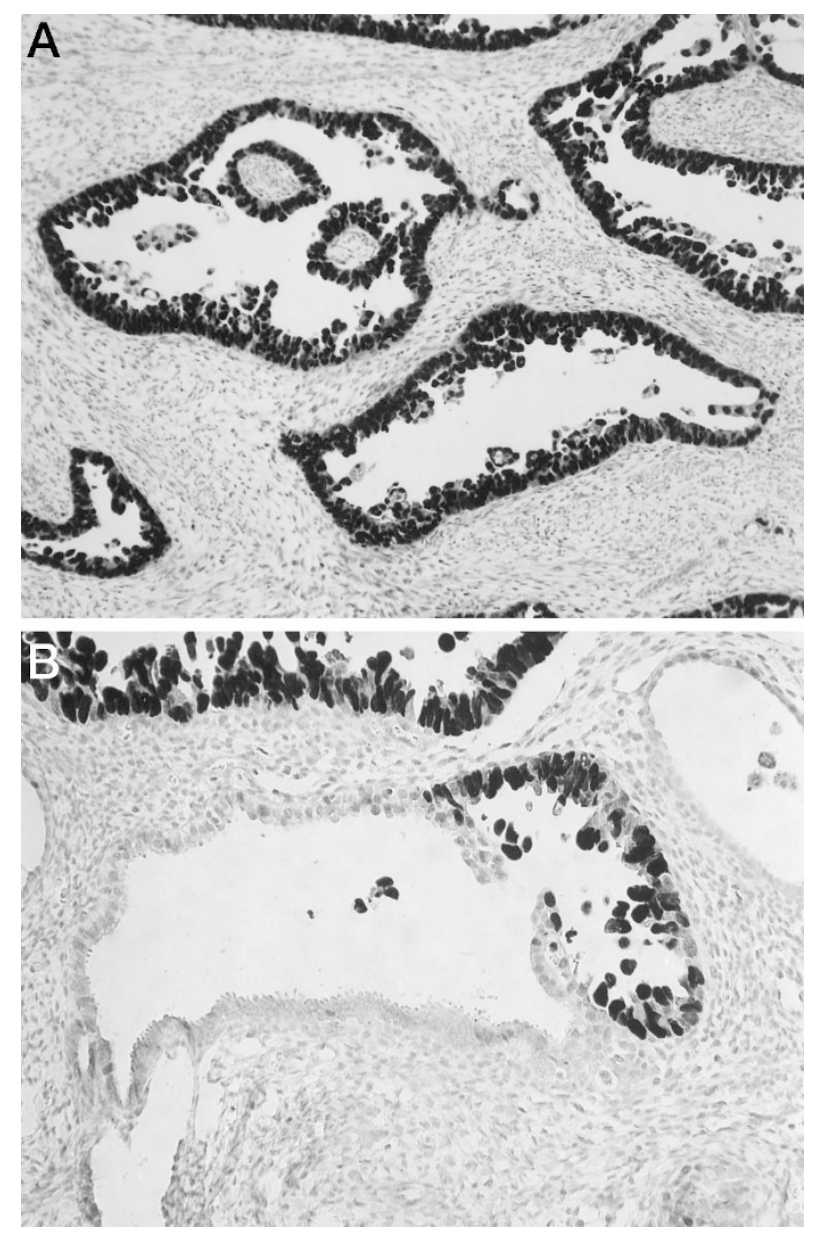

FIGURE 5. A, invasive serous carcinoma, p53 immunohistochemical stain. Cells display diffuse intense nuclear staining. B, endometrial intraepithelial carcinoma, p53 stain. Intense staining for p53 highlights endometrial intraepithelial carcinoma involving surface endometrium and partially replacing endocervical gland. itivity," and other factors $(1,21,22,26-35)$. In our institution, strong diffuse immunopositivity for p53 protein has been strongly associated with p53 mutation in endometrial carcinoma, as determined by sensitive gene sequencing methods (Fig. 5) (22). Use of less than diffuse and intense p53 staining as a cut-off for immunopositivity or reliance on less sensitive $p 53$ mutation assays has not always produced a clear association between immunopositivity and gene mutation. Because p53 mutations may uncommonly lead to a total absence of protein production, immunohistochemical staining is expected to produce some false-negative results. Despite the possibility of both false-positive and falsenegative results, most studies have found that p53 accumulation occurs frequently in serous carcinoma and EIC and less commonly in endometrioid carcinoma. Immunopositivity has been reported more commonly in endometrioid carcinomas that are high grade as opposed to those that are low grade, and nearly all of the endometrial hyperplasias tested have been negative.

Mutations at specific loci in the p53 gene have been linked to predisposing exposures and their respective tumor types in several organs (36). For example, aflatoxin-related hepatocellular carcinomas, sun-related skin carcinomas, and lung carcinomas in smokers have all been associated with mutations at certain loci within the $p 53$ gene. Similar associations have not been established in serous carcinoma; however, the consistent identification of p53 mutations in serous carcinomas may suggest that an environmental exposure, hypoxia, or another factor associated with p53 mutation may be involved. Interestingly, uterine serous carcinoma does not seem to be characteristic of the Li-Fraumeni syndrome in which patients with germline $p 53$ mutations show a strong predisposition to developing other types of cancer. Therefore, many factors other than p53 mutation must be involved in the pathogenesis of these tumors.

\section{Microsatellite Instability}

Microsatellites are short, highly polymorphic tracts of simple repeating units that are widely dispersed throughout the genome and are usually noncoding (37). It is believed that the repetitive nature of microsatellite sequences predisposes to DNA replication errors but that the lengths of these tracts are scrupulously maintained in normal cells by robust DNA repair mechanisms. Microsatellite instability (MI) refers to alterations in the lengths of these repetitive sequences in tumor DNA as compared with normal DNA obtained from the same person. Because the microsatellite regions that are examined in assays for MI are usually noncoding, the significance of MI in these assays is that it 
represents a marker for defects in mismatch repair mechanisms rather than a mutation in a specific gene. On the basis of theoretical calculations, it takes multiple mutations in a single cell to develop cancer, which is unlikely to occur in normal cells with intact repair mechanisms and low spontaneous mutation rates. However, mismatch repair defects, such as those indicated by MI, could result in increased spontaneous mutation rates, potentially permitting a cell to acquire sufficient mutations for the development of cancer (38).

MI has been identified in about $20 \%$ of endometrioid (type 1) carcinomas and associated AHs, but is almost never found in pure serous tumors (39-46). Because MI does not seem to be a frequent finding in endometrial hyperplasia that has not progressed to endometrioid carcinoma, MI may be a late event in the transition from $\mathrm{AH}$ to carcinoma. Given that it is difficult to distinguish some cases of well-developed AH from the earliest examples of Grade 1 endometrioid carcinoma, exact determination of when MI occurs in the pathogenesis of endometrioid carcinoma may be challenging. MI has been identified in mixed endometrioid and serous tumors (46), but we postulate that these alterations are related to the development of the endometrioid component.

Germline mutations in mismatch repair genes have been identified in endometrial cancers associated with hereditary nonpolyposis colorectal cancer syndrome but rarely in sporadic endometrial cancers. Recent studies have suggested that inactivation of mismatch repair genes may result from hypermethylation of promoter regions, resulting in loss of repair function without mutation (epigenetic effect) (47).

\section{Mutation in PTEN}

$P T E N$ is a tumor suppressor gene that derives its name from its preserved tyrosine phophatase domain and its sequence homology with the matrix protein tensin. Germline PTEN mutations have been identified in hereditary cancer syndromes, including Cowden's disease and Bannayan-Zonona syndrome. PTEN mutations have been identified in approximately $40 \%$ of endometrioid carcinomas and in both AHs associated with carcinoma and those that have not progressed to invasive carcinoma (48-51). Mutations in PTEN have been identified in up to $86 \%$ of endometrioid carcinomas with MI, suggesting a relationship between these lesions, although the mutations in PTEN do not involve microsatellite sequences. The PTEN gene has also been described under the acronym "MMAC 1," which stands for mutated in multiple advanced cancer 1 . This name refers to the association of PTEN mutations with aggressive behavior in most tumor systems. However, in endometrioid carcinoma, PTEN mutations have been associated with Grade 1 endometrioid carcinomas having a favorable prognosis in some series.

\section{Mutation in ras}

Mutations in the ras oncogene have been identified in approximately $20 \%$ of endometrioid carcinomas but are not found in serous tumors (52-56). It has been suggested that ras mutations may be detected more frequently in Japan, a country with a historically low endometrial cancer incidence, and less frequently in the United States, where rates are higher.

\section{Hormone Receptors}

Estrogen and progesterone receptors are usually identifiable in endometrial hyperplasia and in endometrioid carcinomas, especially those that are low grade (57). Serous carcinomas and EIC are generally negative for receptors when evaluated with reliable immunohistochemical techniques, but early reports using biochemical methods to test tissue extracts reported positivity, most likely reflecting contamination of the samples with normal endometrium or myometrium, both of which are rich in receptor protein. It is interesting that EIC and serous carcinoma lack receptors, but the atrophic endometrium in which these tumors arise is receptor positive. Theoretically, this could explain why oral contraceptives might be protective for serous carcinoma, even though hormonal therapy is ineffective in treating these tumors.

\section{Clonality}

Studies have demonstrated that $\mathrm{AH}$ is a clonal lesion and when associated with endometrioid carcinoma, $\mathrm{AH}$ is derived from the same clone as the tumor (58-59). Benign endometrium and other types of endometrial hyperplasia do not appear clonal with the assays that have been used. If one views clonality as a test for neoplasia, then $\mathrm{AH}$ could be viewed as a form of noninvasive neoplasm.

\section{SUMMARY OF MOLECULAR DATA}

In summary, molecular evidence, though not abundant or entirely consistent between studies, supports the existence of a dualistic model of endometrial carcinogenesis. Endometrioid (type 1) carcinomas are associated with mutations in ras, PTEN, and MI, whereas serous (type 2) carcinomas are associated with p53 mutations. The coherence of the molecular findings between the carcinomas 


\section{Type I Pathway}

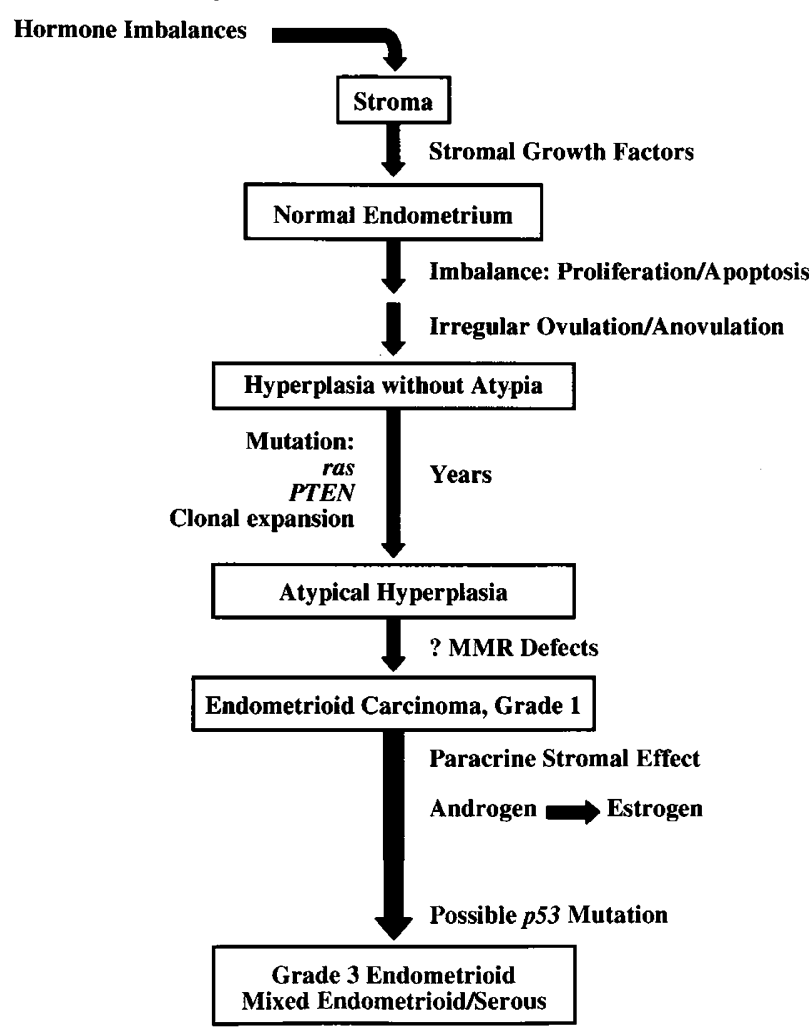

FIGURE 6. Dualistic model of endometrial carcinogenesis, type 1 pathway. ?MMR, possible role for mismatch repair defects.

and their respective precursors supports the view that $\mathrm{AH}$ is the immediate precursor of endometrioid carcinoma and that EIC is the precursor of serous tumors.

\section{CLASSIC PATHWAY OF ENDOMETRIAL CARCINOGENESIS (GENESIS OF TYPE 1 TUMORS)}

Details of the proposed "classic" pathway of endometrial carcinogenesis are summarized in Figure 6. Many endometrioid carcinomas (type 1 tumors) develop in the setting of excess estrogen relative to progesterone. These imbalances may result from absolute excesses of endogenous or exogenous estrogen or relative deficiencies of progesterone. Androgens and other growth factors may also play a role in this pathway, but this has not been well studied. Hormone levels reflect multiple interrelated processes including exposure (exogenous intake + endogenous production), catabolism, and excretion, which in turn reflect the levels and functional activity of specific metabolic enzymes in the uterus, liver, and other organs. Because hormone balance reflects complex gene-environment interactions, every woman has her own unique hormonal physiology, which may vary over her lifetime.
To further complicate the process, estrogen imbalance may be systemic or occur locally within the endometrium. Systemic estrogenism may be assessed by evaluating risk factor data and serum hormone levels, but interpretation of these data has been confusing, suggesting that simultaneous assessment of local tissue levels might be informative (10). Measurement of tissue hormone levels is a new, technically challenging area that suffers from some of the same limitations as single serum measurements obtained in case-control studies; it reflects only a single point in time when a tumor is already present.

Historically, estrogen has been viewed as directly promoting endometrial carcinogenesis by stimulating rapid proliferation of epithelial cells. However, recent experimental data suggest that estrogen may produce diverse effects and that some of the actions on epithelial cells may be mediated by endometrial stroma. For example, aromatase activity has been identified in extracts of tumor tissue using biochemical techniques (60), but Wantanabe et al. (61), using immunohistochemical and in situ hybridization, have localized the source of aromatase in tumor masses to the desmoplastic stroma surrounding the neoplastic cells rather than the tumor cells. In this study, aromatase protein and message were not found in normal or hyperplastic endometrium. These data suggest that invasive carcinoma may induce aromatase activity in desmoplastic stroma, which in turn could provide paracrine stimulation to an already established invasive carcinoma. The absence of aromatase activity in normal and hyperplastic endometrium suggests that local estrogen production within the uterus may not precede and promote the development of cancer, but it could play a role in its progression. This may challenge the classic view that endometrial cancer risk is merely a matter of excess estrogen exposure, because neither elevated serum estrogens (albeit based on single measurements) nor local production of estrogen in benign endometrium seems to adequately account for endometrial cancer risk. Future investigations to confirm and extend these findings are needed.

Observations produced by transplanting various combinations of stroma and epithelial cells obtained from wild type and estrogen receptor knockout mice into nude mice have also demonstrated the importance of epithelial-stromal interactions in endometrial carcinogenesis (62). Transplants of estrogen receptor-negative stroma and estrogen receptor-positive epithelial cells do not proliferate in response to exogenous estrogen. However, if estrogen receptor-positive stroma is transplanted with estrogen receptor-negative epithelium, the epithelial cells demonstrate receptor-dependent proliferation. If confirmed in human tissues, this would 
suggest that stroma directs the estrogen-dependent proliferative response in epithelial cells.

Finally, data suggest that the role of estrogen in carcinogenesis is not limited to stimulating proliferation. Experimental data suggest that the p450 enzyme, CYP 1B1, which is widely distributed in many human organs, can transform estrogens into 4-hydroxy catechols that may produce DNA damage (63). Therefore, high tissue levels of estrogen could theoretically promote carcinogenesis via two mechanisms: producing DNA damage and stimulating proliferation.

The development of endometrial hyperplasia and endometrioid carcinoma (type 1 tumors) in women with irregular or anovulatory cycles suggests that prolonged periods without endometrial sloughing may be important in the development of fixed endometrial lesions. Although risk factors may be operative in premenopausal women, initiating events occurring in young women may be masked as a result of periodic endometrial shedding. However, these occult alterations may develop into hyperplasia or neoplasia in the postmenopausal period. Because anovulatory states are often associated with concurrent hormone imbalances, entangling the relative importance of these two potential mechanisms would be difficult. Nevertheless, progression of endometrial hyperplasia, including $\mathrm{AH}$, to invasion is neither inevitable nor rapid.

The identification of $\mathrm{MI}$ in $\mathrm{AH}$ associated with endometrioid carcinomas, but not in $\mathrm{AH}$ without associated carcinoma, suggests that mismatch repair defects may occur in the transition between the two lesions. The factors that are related to the acquisition of atypia in endometrial hyperplasia have not been well studied, but data suggest that $\mathrm{AH}$ shares features with carcinoma that are not found in hyperplasia without atypia. Specifically, AH seems to represent a clonal lesion associated with MI and mutations in ras and PTEN. In addition, cells of debated histogenesis, referred to as "foam" cells, are a frequent finding in carcinoma and its well-developed precursors, and they may be involved in tumor development through production of inflammatory mediators that stimulate aromatase production and proliferation. The relationship between endometritis and endometrial carcinoma has received little attention. The molecular changes associated with the development of myometrial invasion require further study, because endometrioid tumors without myometrial invasion almost never metastasize. In fact, some of the criteria for the diagnosis of early endometrial carcinoma, such as the development of back-to-back glands and papillae formation, are often cited as examples of "stromal invasion," but nonmorphologic support for this dogma is lacking.
Histopathologic examination suggests that Grade 3 endometrioid carcinomas develop from Grade 1 tumors that have undergone clonal evolution and dedifferentiation. This process of tumor progression may be associated with loss of hormone receptor expression and the development of p53 mutations. The development of malignant mixed mullerian tumors (or carcinosarcomas) may represent another pathway of dedifferentiation in a preexisting carcinoma, because clinicopathologic, ultrastructural, immunohistochemical, and molecular evidence suggests that the sarcomatous component represents divergent differentiation of the epithelial component (64-67). Accordingly, many pathologists view these tumors as "metaplastic carcinomas."

\section{ALTERNATIVE PATHWAY (GENESIS OF TYPE II TUMORS)}

The proposed "alternative" pathway of endometrial carcinogenesis is outlined in Figure 7. Serous carcinoma typically develops in elderly women with atrophic endometrium. Risk factors for serous carcinoma have not been identified, but available evidence suggests that excess estrogen exposure is not a risk factor for the development of serous tumors. Therefore, the only definite risk factor for serous carcinoma is age. Serous carcinomas are

\section{Type II Pathway}

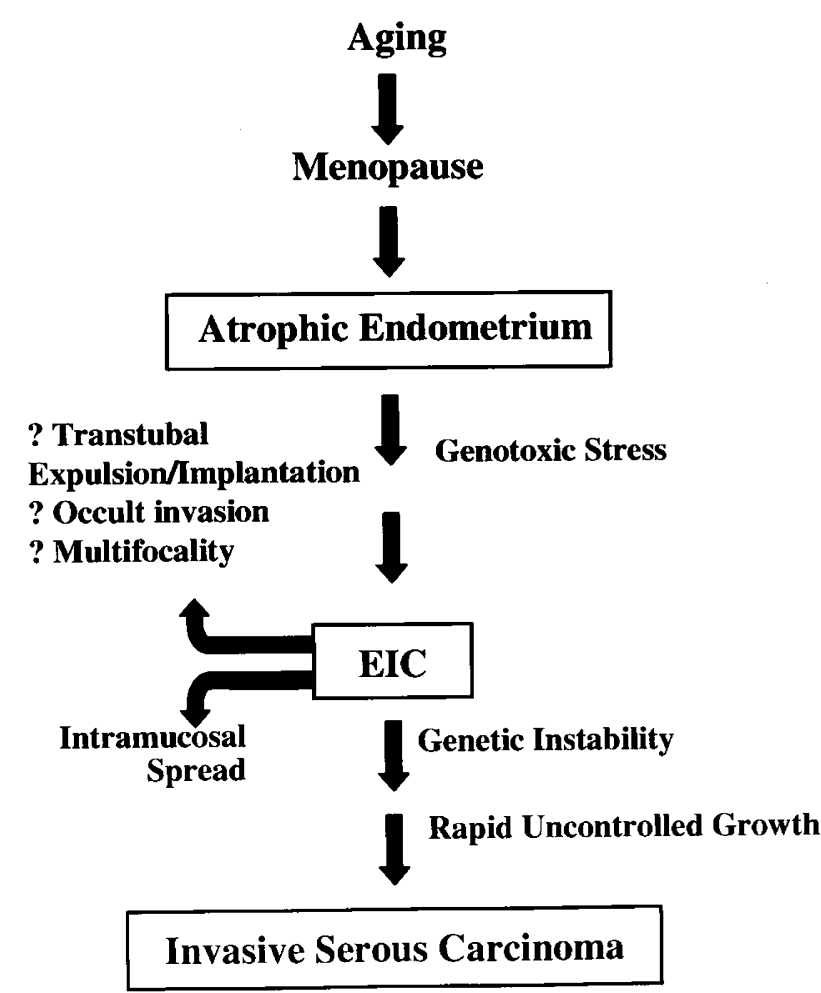

FIGURE 7. Dualistic model of endometrial carcinogenesis, type 2 pathway. EIC, endometrial intraepithelial carcinoma. 
usually diagnosed in women over 60 , and these neoplasms are exceedingly uncommon in younger women. One possible approach to understanding the etiology of these tumors is to examine factors that seem related to the development of $p 53$ mutations in experimental systems. The nearly universal detection of $p 53$ mutations in serous carcinoma and its precursor, EIC, including examples of EIC without associated invasion, suggests that $p 53 \mathrm{mu}-$ tation may represent the molecular signature of serous carcinoma and possibly define the entity in combination with morphology. Mixed tumors displaying serous differentiation associated with endometrioid differentiation or other histologic patterns may not arise directly from atrophic endometrium and could therefore have an entirely different pathogenesis.

From a histopathologic perspective, serous carcinomas seem to develop rapidly from EIC in the setting of endometrial atrophy in an estrogendeficient hormonal milieu. However, the observation that EIC may remain stable without treatment for up to 17 months challenges this view. Paradoxically, the aggressive behavior of extrauterine tumor in patients with pure EIC suggests that the cells that compose EIC possess many of the biologic features of full-blown serous carcinoma.

The development of sarcomatous differentiation in serous tumors presumably occurs through a process of clonal evolution akin to what has been postulated for endometrioid tumors. In one study, malignant mixed mullerian tumors with an epithelial component showing serous differentiation were more often associated with EIC, whereas endometrial hyperplasia was identified more often in uteri containing malignant mixed mullerian tumors with an epithelial component showing endometrioid differentiation (68).

\section{FUTURE DIRECTIONS}

Future studies are needed to understand the critical transitions that occur in the classic pathway of type 1 carcinogenesis: (1) the development of atypical hyperplasia from hyperplasia without atypia and (2) the development of invasion. Continued search for etiologic heterogeneity within tumors diagnosed as endometrioid carcinoma may be worthwhile, because hyperplasia is not identified in a significant proportion of uteri containing these tumors. Identifying risk factors for serous (type 2) carcinomas and elucidating the changes in atrophic endometrium that precede the development of EIC would also be of interest. Attempts to study the pathogenesis of unusual types of carcinoma, such as clear cell carcinoma, may be useful because of the aggressive nature of these neoplasms. Immuno- histochemical studies suggest that these tumors may have a unique phenotype with respect to receptor status and p53 accumulation (69). The role of endometrial stroma in carcinogenesis and progression and the mechanisms of estrogen action in promoting proliferation and possibly acting as a procarcinogen are provocative and deserve systematic study in human tissues. Studies of genetic polymorphisms in key hormone metabolizing enzymes may have application in identifying women at risk for endometrial carcinoma and in understanding hormonal mechanisms related to carcinogenesis. Finally, determining the earliest alterations that commit cells to tumor development may be useful in identifying neoantigens that could be targets for early detection and treatment. It is hoped that studies successfully addressing these and other questions will provide a clearer picture of endometrial carcinogenesis and give us better tools to prevent, detect, and treat patients with these tumors.

\section{REFERENCES}

1. Sherman ME, Bur ME, Kurman RJ. p53 in endometrial cancer and its putative precursors: evidence for diverse pathways of tumorigenesis. Hum Pathol 1995;26:1268-74.

2. Bokhman JV. Two pathogenetic types of endometrial carcinoma. Gynecol Oncol 1983;15:10-7.

3. Parker SL, Tong T, Bolden, Wingo PA. Cancer statistics, 1996. CA Cancer J Clin 1996;65:5-27.

4. Grady D, Ernster VL. Endometrial cancer. In: Schottenfeld D, Fraumeni JF Jr, editors. Cancer epidemiology and prevention. 2nd ed. New York: Oxford University Press; 1996. p. 1058-89.

5. Barrett RJ II, Harlan LC, Wesley MN, Hill Ha, Chen VW, Clayton LA, et al. Endometrial cancer: stage at diagnosis and associated factors in black and white patients. Am J Obstet Gynecol 1995;173:414-23.

6. Hicks ML, Kim W, Abrams J, Johnson CC, Blount AC, Parham GP. Racial differences in surgically staged patients with endometrial cancer. J Natl Med Assoc 1997;89:134-40.

7. Hill HA, Eley JW, Harlan LC, Greenberg RS, Barrett RJ, Chen VW. Racial differences in endometrial cancer survival: the black/white cancer survival study. Obstet Gynecol 1996;88: 919-26.

8. Liu JR, Conaway M, Rodriguez GC, Soper JT, Clarke-Pearson DL, Berchuck A. relationship between race and interval to treatment in endometrial cancer. Obstet Gynecol 1995;86: 486-90.

9. Sherman ME, Sturgeon S, Brinton LA, Potischman N, Kurman RJ, Berman ML, et al. Risk factors and hormone levels in patients with serous and endometrioid uterine carcinomas. Mod Pathol 1997;10:963-8.

10. Potischman N, Hoover RN, Brinton LA, Siiteri P, Dorgan JF, Swanson CA, et al. A case-control study of endogenous steroid hormones and endometrial cancer. J Natl Cancer Inst 1996;88:1127-35.

11. Sturgeon SR, Sherman ME, Kurman RJ, Berman ML, Mortel R, Twiggs LB, et al. Analysis of histopathological features of endometrioid uterine carcinomas and epidemiologic risk factors. Cancer Epidemiol Biomarkers Prev 1998;7:231-5.

12. Hendrickson M, Ross J, Eifel P, Cox RS, Martinez A, Kempson R. Uterine papillary serous carcinoma: a highly malignant form of endometrial adenocarcinoma. Am J Surg Pathol 1982;6:93-108. 
13. Sherman ME, Bitterman P, Rosenshein NB, Delgado G, Kurman RJ. Uterine serous carcinoma: a morphologically diverse neoplasm with unifying clinicopathologic features. Am J Surg Pathol 1992;16:600-10.

14. Kurman RJ, Kaminski PF, Norris HJ. The behavior of endometrial hyperplasia. A long-term study of "untreated" hyperplasia in 170 patients. Cancer 1985;56:403-12.

15. Randall TC, Kurman RJ. Progestin treatment of atypical hyperplasia and well-differentiated carcinoma of the endometrium in women under age 40. Obstet Gynecol 1997;90:434-40.

16. Kim YB, Holschneider CH, Ghosh K, Nieberg RK, Montz FJ. Progestin alone as primary treatment of endometrial carcinoma in premenopausal women. Report of seven cases and review of the literature. Cancer 1997;320-7.

17. Ferenczy A, Gelfand M. The biologic significance of cytologic atypia in progestogen-treated endometrial hyperplasia. Am J Obstet Gynecol 1989;160:126-31.

18. Ambros RA, Sherman ME, Zahn CM, Bitterman P, Kurman RJ. Endometrial intraepithelial carcinoma: a distinctive lesion specifically associated with tumors displaying serous differentiation. Hum Pathol 1995;26:1260-7.

19. Carcangiu ML, Chambers JT. Uterine papillary serous carcinoma: a study of 108 cases with emphasis on the prognostic significance of associated endometrioid carcinoma, absence of invasion, and concomitant ovarian carcinoma. Gynecol Oncol 1992;47:298-305.

20. Spiegel GW. Endometrial carcinoma in situ in postmenopausal women. Am J Surg Pathol 1995;19:417-32.

21. Zheng W, Khurana R, Farahmand S, Wang Y, Zhang Z, Felix JC. p53 immunostaining as a significant adjunct diagnostic method for uterine surface carcinoma. Am J Surg Pathol 1998;22:163-73.

22. Tashiro H, Isacson C, Levine R, Kurman RJ, Cho KR, Hedrick L. p53 gene mutations are common in uterine serous carcinoma and occur early in their pathogenesis. Am J Pathol 1997;150:177-85.

23. Lee KR, Belinson JL. Recurrence in noninvasive endometrial carcinoma. Am J Surg Pathol 1991;15:965-73.

24. Goff BA, Kata D, Schmidt RA. Uterine papillary serous carcinoma: patterns of metastatic spread. Gynecol Oncol 1994; $54: 264-8$

25. Silva EG, Jenkins R. Serous carcinoma in endometrial polyps. Mod Pathol 1990;3:120-8.

26. Ambros RA, Ross JS, Kallakury BV, Malfetano J, Kim Y, Hwang J, et al. p53 gene status in endometrial carcinomas showing diffuse positivity for p53 protein by immunohistochemical analysis. Mod Pathol 1995;8:441-5.

27. Ambros RA, Sheehan CE, Kallakury BV, Ross JS, Malfetano J, Paunovich E, et al. MDM2 and p53 protein expression in the histologic subtypes of endometrial carcinoma. Mod Pathol 1996;9:1165-9.

28. Bur ME, Perlman C, Edelman L. p53 expression in neoplasms of the uterine corpus. Am J Clin Pathol 1992;98:81-7.

29. Ito K, Sasano H, Matsunaga G, Sato S, Yajima A, Nasim S, et al. Correlations between p21 expression and clinicopathologic findings, p53 gene and protein alterations, and survival in patients with endometrial carcinoma. J Pathol 1997;183: $318-24$

30. Jiko K, Sasano H, Ito K, Ozawa N, Sato S, Yajima A. Immunohistochemical, and in situ hybridization analysis of p53 in human endometrial carcinoma of the uterus. Anticancer Res 1993;13:305-10.

31. King SA, Adas AA, LiVolsi VA, Takahashi H, Behbakht K, McGovern P, et al. Expression and mutation analysis of the p53 gene in uterine papillary serous carcinoma. Cancer 1995;75:2700-5.

32. Kohler MF, Nishii H, Humphrey PA, Saski H, Marks J, Bast $\mathrm{RC}$, et al. Mutation of the p53 tumor-suppressor gene is not a feature of endometrial hyperplasia. Am J Obstet Gynecol 1993;169:690-4.

33. Kohler MF, Berchuck A, Davidoff AM, Humphrey PA, Dodge $\mathrm{RK}$, Iglehart JD, et al. Overexpression and mutation of $p 53$ in endometrial carcinoma. Cancer Res 1992;52:1622-7.

34. Moll UM, Chalas E, Auguste M, Meaney D, Chumas J. Uterine papillary serous carcinoma evolves via a p53-driven pathway. Hum Pathol 1996;27:1295-300.

35. Soslow RA, Shen PU, Chung MH, Isacson C. Distinctive p53 and mdm2 immunohistochemical expression profiles suggest different pathogenetic pathways in poorly differentiated endometrial carcinoma. Int J Gynecol Pathol 1998;17:129-34.

36. Hussain SP, Harris CC. Molecular epidemiology of human cancer: contribution of mutation spectra studies of tumor suppressor genes. Cancer Res 1998;58:4023-37.

37. Eschelman JR, Markowitz SD. Microsatellite instability in inherited and sporadic neoplasms. Curr Opin Oncol 1995;7:83-9.

38. Loeb LA. Microsatellite instability: marker of a mutator phenotype in cancer. Cancer Res 1994;54:5059-63.

39. Burks RT, Kessis TD, Cho KR, Hedrick L. Microsatellite instability in endometrial carcinoma. Oncogene 1994;11:1163-6.

40. Caduff RF, Johnston CM, Svoboda-Newman SM, Poy EL, Merajver SD, Frank TS. Clinical and pathological significance of microsatellite instability in sporadic endometrial carcinoma. Am J Pathol 1996;148:1671-8.

41. Duggan BD, Felix JC, Muderspach LI, Tourgeman D, Zheng J, Shibata D. Microsatellite instability in sporadic endometrial carcinoma. J Natl Cancer Inst 1994;86:1216-21.

42. Mutter GL, Boynton KA, Faquin WC, Ruiz RE, Jovanovic AS. Allelotype mapping of unstable microsatellites establishes direct lineage continuity between endometrial precancers and cancer. Cancer Res 1996;56:4483-6.

43. Peiffer SL, Herzog TJ, Tribune DJ, Mutch DG, Gersell DJ, Goodfellow PJ. Allelic loss of sequences from the long arm of chromosome 10 and replication errors in endometrial cancers. Cancer Res 1995;55:1922-6.

44. Risinger JI, Berchuck A, Kohler MF, Watson P Lynch HT, Boyd J. Genetic instability of microsatellites in endometrial carcinoma. Cancer Res 1993;53:5100-3.

45. Tashiro H, Lax SF, Gaudin PB, Isacson C, Cho KR, Hedrick L. Microsatellite instability is uncommon in uterine serous carcinoma. Am J Pathol 1997;150:75-9.

46. Catasus L, Machin P, Matias-Guiu X, Prat J. Microsatellite instability in endometrial carcinomas. Clinicopathologic correlations in a series of 42 cases. Hum Pathol 1998;29: $1160-4$.

47. Gurin CC, Federici MG, Kang L, Boyd J. Causes and consequences of microsatellite instability in endometrial carcinoma. Cancer Res 1999;59:462-6.

48. Levine RL, Cargile CB, Blazes MS, van Rees B, Kurman RJ, Ellenson LH. PTEN mutations and microsatellite instability in complex atypical hyperplasia, a precursor lesion to uterine endometrioid carcinoma. Cancer Res 1998;58:3524-8.

49. Maxwell GL, Risinger JI, Gumbs C, Shaw H, Bentley RC, Barrett JC, et al. Mutation of the PTEN tumor suppressor gene in endometrial hyperplasias. Cancer Res 1998;58:2500-3.

50. Risinger JI, Hayes AK, Berchuck A, Barrett JC. PTEN/MMAC1 mutations in endometrial cancers. Cancer Res 1997;57:4736-8.

51. Tashiro H, Blazes MS, Wu R, Cho KR, Bose S, Wang SI, et al. Mutations in PTEN are frequent in endometrial carcinoma but rare in other common gynecological malignancies. Cancer Res 1997;57:3935-40.

52. Boyd J, Risinger JI. Analysis of oncogene alterations in human endometrial carcinoma: prevalence of ras mutations. Mol Carcinog 1991;4:189-95.

53. Caduff RF, Johnston CM, Frank TS. Mutations of the Ki-ras oncogene in carcinoma of the endometrium. Am J Pathol 1995;146:182-8.

54. Enomoto T, Inoue M, Perantoni AO, Buzard GS, Miki H, 
Tanizawa $\mathrm{O}$, et al. K-ras activation in premalignant and malignant epithelial lesions of the human uterus. Cancer Res 1991;51:5308-14.

55. Ignar-Trowbridge D, Risinger JI, Dent GA, Kohler M, Berchuck A, McLachlan JA, et al. Mutations of the Ki-ras oncogene in endometrial carcinoma. Am J Obstet Gynecol 1992; $167: 227-32$.

56. Sasaki H, Nishii H, Takahashi H, Tada A, Furusato M, Terashima $\mathrm{Y}$, et al. Mutation of the Ki-ras protooncogene in human endometrial hyperplasia and carcinoma. Cancer Res 1993;53:1906-10.

57. Nyholm HCJ, Nielsen AL, Lyndrup J, Norup P, Thorpe SM. Biochemical and immunohistochemical estrogen and progesterone receptors in adenomatous hyperplasia and endometrial carcinoma: correlations with stage and other clinicopathologic features. Am J Obstet Gynecol 1992;167:133442.

58. Esteller M, Garcia A, Martinez-Palones JM, Xercavins J, Reventos J. Detection of clonality and genetic alterations in endometrial pipelle biopsy and its surgical specimen counterpart. Lab Invest 1997;76:109-16.

59. Mutter GL, Chaponot ML, Fletcher JA. A polymerase chain reaction assay for non-random $\mathrm{X}$ chromosome inactivation identifies monoclonal endometrial cancers and precancers. Am J Pathol 1995;146:501-8.

60. Bulun SE, Economos K, Miller D, Simpson ER. CYP19 (aromatase cytochrome P450) gene expression in human malignant endometrial tumors. J Clin Endocrinol Metab 1994;79: 1831-4.

61. Wantanabe K, Sasano H, Harada N, Ozaki M, Niikura H, Sato $\mathrm{S}$, et al. Aromatase in human endometrial carcinoma and hyperplasia. Immunohistochemical, in situ hybridization, and biochemical studies. Am J Pathol 1995;146:491-500.

62. Cooke PS, Buchanan DL, Young P, Setiawan T, Brody J, Korach KS, et al. Stromal estrogen receptors mediate mitogenic effects of estradiol on uterine epithelium. Proc Natl Acad Sci U S A 1997;94:6535-40.

63. Yager JD, Liehr JG. Molecular mechanisms of estrogen carcinogenesis. Ann Rev Pharmacol Toxicol 1996;36:203-32.

64. Bitterman P, Chun B, Kurman RJ. The significance of epithelial differentiation in mixed mesodermal tumors of the uterus. A clinicopathologic and immunohistochemical study. Am J Surg Pathol 1990;14:317-28.

65. de Brito PA, Silverberg SG, Orenstein JM. Carcinosarcoma (malignant mixed mullerian (mesodermal) tumor) of the female genital tract: immuno-histochemical and ultrastructural analysis of 28 cases. Hum Pathol 1993;24:132-42.

66. Emoto M, Iwasaki H, Kikuchi M, Shirakawa K. Characteristics of cloned cells of mixed mullerian tumor of the human uterus. Carcinoma cells showing myogenic differentiation in vitro. Cancer 1993;71:3065-75.

67. Gorai I, Doi C, Minaguchi H. Establishment and characterization of carcinosarcoma cell line of the human uterus. Cancer 1993;71:775-86.

68. Ambros R, Sherman M, Zahn C, Bitterman P, Kurman RJ. Association of endometrial hyperplasia and endometrial intraepithelial carcinoma and malignant mixed mullerian tumors [abstract]. Mod Pathol 1993;6:72A.

69. Lax SF, Pizer ES, Ronnett BM, Kurman RJ. Clear cell carcinoma of the endometrium is characterized by a distinctive profile of p53, Ki-67, estrogen, and progesterone receptor expression. Hum Pathol 1998;29:551-8.

\section{Book Review}

\section{Wetli CV, Mittleman RE, Rao VJ: An Atlas of Forensic Pathology, 286 pp, Chicago, American Society of Clinical Pathologists, 1999 (\$165).}

Forensic pathology is an empirical science that cannot be learned from books; there is no easy way around it, and the only way to become a forensic pathologist is to do it, if you have the stomach. This atlas is not a substitute for such training; nevertheless, its incredible collection of well-chosen pictures is as good a substitute as you can get.

This atlas, a compact compendium of forensic pathology, is an ideal quick review for residents and practicing hospital pathologist. Resi- dents, this book could definitely help you pass the examinations. Hospital pathologists, if you are acting as part-time coroners, you could find in this book enough hints on how to handle various cases of suicide, murder, or traffic injuries and much more at the same time. This book also should be available to nonpathologists. All of us might from time to time be confronted with the task of dealing with an unusual death, and this book could serve as a quick reference to tide you over until the forensic team arrives.

\section{Ivan Damjanov \\ University of Kansas School of Medicine Kansas City, Kansas}

